Cite this: Nanoscale, 2014, 6, 4379

\title{
Enhancement of seawater corrosion resistance in copper using acetone-derived graphene coating $\dagger$
}

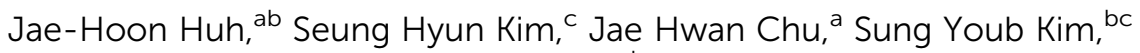 \\ Ji Hyun Kim ${ }^{\star a c}$ and Soon-Yong Kwon ${ }^{\star a b c}$
}

We show that acetone-derived graphene coating can effectively enhance the corrosion efficiency of copper $(\mathrm{Cu})$ in a seawater environment $(0.5-0.6 \mathrm{M}$ ( 3.0-3.5\%) sodium chloride). By applying a drop of acetone $\left(\sim 20 \mu \mathrm{cm}^{-2}\right)$ on Cu surfaces, rapid thermal annealing allows the facile and rapid synthesis of graphene films on Cu surfaces with a monolayer coverage of almost close to $100 \%$. Under optimal growth conditions, acetone-derived graphene is found to have a relatively high crystallinity, comparable to common graphene grown by chemical vapor deposition. The resulting graphene-coated $\mathrm{Cu}$ surface exhibits 37.5 times higher corrosion resistance as compared to that of mechanically polished $\mathrm{Cu}$. Further, investigation on the role of graphene coating on $\mathrm{Cu}$ surfaces suggests that the outstanding corrosion inhibition efficiency (IE) of $97.4 \%$ is obtained by protecting the underlying $\mathrm{Cu}$ against the penetration of both dissolved oxygen and chlorine ions, thanks to the closely spaced atomic structure of the graphene sheets. The increase of graphene coating thickness results in the enhancement of the overall corrosion IE up to $\sim 99 \%$, which can be attributed to the effective blocking of the ionic diffusion process via grain boundaries. Overall, our results suggest that the acetone-derived graphene film can effectively serve as a corrosion-inhibiting coating in the seawater level and that it may have a promising role to play for potential offshore coating.

Received 11th November 2013
Accepted 31st January 2014

DOI: $10.1039 / c 3 n r 05997 a$

www.rsc.org/nanoscale seawater, the temperature, the velocity of water flowing past the metal surface, and the degree and kind of pollution. ${ }^{3}$

Considering that the metallic corrosion process is normally electrochemical and it ordinarily begins at the surface, one promising approach for reducing it would be to develop a controllable physical barrier to corrosion in the form of films and coatings. Many different approaches, including coating with polymers, ${ }^{4}$ organic layers ${ }^{5,6}$ and other metals and alloys, ${ }^{7}$ have been developed to protect the copper surface. However, the existing coating technologies typically change the physical properties of copper, such as physical dimensions, appearance, and optical properties, due to the thickness of the coating, and often decrease the thermal and electrical conductivities. To overcome these drawbacks, intense effort is currently underway to find an ultrathin coating with minimum changes in the physical and chemical properties of underlying metals.

Graphene has generated an enormous amount of scientific interest in the research community owing to its ultrathin geometry with fascinating properties. ${ }^{8-11}$ With large-area graphene becoming available, ${ }^{\mathbf{1 2}-16}$ other aspects such as its intermolecular interactions with a wide variety of environments have become increasingly interesting. ${ }^{17-21}$ Graphene may be a strong candidate for ultrathin protective coating of metals considering its structural properties as well as high chemical and thermal stabilities. Recently, several pioneering reports have demonstrated that chemical vapor deposition (CVD)-grown graphene
${ }^{a}$ School of Materials Science and Engineering, Ulsan National Institute of Science and sykwon@unist.ac.kr

${ }^{b}$ Opto-Electronics Convergence Group \& Low Dimensional Carbon Materials Center, Ulsan National Institute of Science and Technology (UNIST), Ulsan 689-798, South Korea

${ }^{c}$ School of Mechanical and Nuclear Engineering, Ulsan National Institute of Science and Technology (UNIST), Ulsan 689-798, South Korea

$\dagger$ Electronic supplementary information (ESI) available. See DOI: 10.1039/c3nr05997a 
films play a role of effective anti-corrosion barriers for electrochemical corrosion of metals. ${ }^{22-24}$ However, most of the electrochemical tests were performed in a relatively low concentration of $0.1 \mathrm{M}(\sim 0.6 \%) \mathrm{NaCl}^{22,23}$ and $0.1 \mathrm{M} \mathrm{Na}_{2} \mathrm{SO}_{4} \cdot{ }^{24}$ To the best of our knowledge, no one has reported yet on the corrosion properties of graphene-coated $\mathrm{Cu}$ in the seawater level (0.5-0.6 M ( 3.0-3.5\%) NaCl).

In this work, we demonstrate that acetone-derived graphene films can effectively protect the metallic growth substrate of $\mathrm{Cu}$ from corrosion in relatively high concentrations of $0.5-0.6 \mathrm{M}$ $(\sim 3.0-3.5 \%)$ NaCl. In our approach, we build a monolayer graphene framework on $\mathrm{Cu}$ surfaces using a drop of acetone via a rapid thermal annealing (RTA) process. The RTA process is short in duration, processing each sample in several minutes with easier process control. The surfaces of the $\mathrm{Cu}$ foils before and after depositing acetone molecules were investigated by X-ray photoelectron spectroscopy (XPS) and attenuated total reflectance Fourier transform-infrared (ATR FT-IR) spectroscopy. We further investigated the potential use of graphene as a corrosion inhibition coating in the seawater level, quantified the degree of corrosion inhibition, and studied the corrosion inhibition mechanism to enhance this behavior using electrochemical methods such as potentiodynamic polarization and electrochemical impedance spectroscopy (EIS) measurements. Our experimental analyses show that the passivation mechanism of single-layer graphene follows characteristics of large cathodic reduction barriers against dissolved oxygen and chloride diffusion into underlying $\mathrm{Cu}$. We also demonstrated a pathway to form a more reliable corrosion inhibition coating layer with a corrosion inhibition efficiency of $~ 99 \%$ by using multi-layer graphene sheets on $\mathrm{Cu}$. This technique may offer a more promising approach to the enhancement of anti-corrosion performance of not only $\mathrm{Cu}$ but also a variety of metals and alloys for potential offshore applications.

\section{Experimental section}

\section{Rapid thermal annealing (RTA) system}

We used $\mathrm{Cu}$ foils (product no. 13382, $25 \mu \mathrm{m}$ thick, 99.8\%, Alfa Aesar) as substrates. The foils were pre-annealed at $600{ }^{\circ} \mathrm{C}$ for 20 min for surface cleaning in an RTA chamber, and then a drop of acetone was applied on the $\mathrm{Cu}$ surface. Acetone was uniformly coated on the $\mathrm{Cu}$ surface by a spin-coating process and dried under ambient conditions. The samples were then annealed at temperatures ranging from $800{ }^{\circ} \mathrm{C}$ to $1000{ }^{\circ} \mathrm{C}$ for 3 min, using an RTA system under vacuum $\left(\sim 10^{-3}\right.$ Torr $)$.

\section{X-ray photoelectron spectroscopy (XPS) analysis}

To compare the elemental composition change in an empirical formula, chemical states of intrinsic impurities such as $\mathrm{C}$ and $\mathrm{O}$ in $\mathrm{Cu}$ foils before and after RTA, XPS investigations were done on a K-alpha spectrometer (Thermo Fisher) using $\mathrm{Al} \mathrm{K \alpha}$ nonmonochromatic X-ray excitation at a power of $72 \mathrm{~W}$, with an analysis area of $\sim 0.4 \mathrm{~mm}$ in diameter and a pass energy of $50 \mathrm{eV}$ for electron analysis. For sputter depth profiling in this study, $\mathrm{Ar}^{+}$ions of $1 \mathrm{keV}$ energy at a scan size of $2 \mathrm{~mm} \times 2 \mathrm{~mm}$ and a sputter interval of $3 \mathrm{~s}$ were used, which resulted in a typical sputter rate of $0.18 \mathrm{~nm} \mathrm{~s}^{-1}$ for $\mathrm{Cu}$ foils.

\section{Attenuated total reflectance Fourier transform-infrared (ATR FT-IR) spectroscopy}

FT-IR was used to record the reflectance spectra of thermally annealed $\mathrm{Cu}$ foil samples $\left(600^{\circ} \mathrm{C}, 20 \mathrm{~min}\right) \mathrm{using}$ a Germanium ATR crystal before and after acetone deposition.

\section{Raman spectroscopy}

The presence of graphene layers was confirmed by Raman spectroscopy. The Raman spectra were collected from either the graphene films on the $\mathrm{Cu}$ surface or after being transferred onto a $300 \mathrm{~nm}$ thick $\mathrm{SiO}_{2}$ layer on $\mathrm{Si}$ and were also collected from the graphene films after corrosion tests. Raman spectroscopy was carried out with a WiTec alpha 300R M-Raman system at $532 \mathrm{~nm}$ excitation and the laser spot size was $\sim 500 \mathrm{~nm}$ in diameter when focused with a $50 \times$ optical lens. The Raman spectra from every spot of the sample were recorded, and the data analysis was conducted using the WiTec Project software.

\section{Field emission scanning electron microscopy (FE-SEM)}

Corrosion product analysis of the as-received, mechanically polished and graphene-coated $\mathrm{Cu}$ samples before and after the corrosion test was performed by SEM (Cold-SEM, Hitachi) equipped with an energy dispersive X-ray spectrometer (EDS).

\section{Electrochemical corrosion tests}

The as-received, mechanically polished, and graphene-coated $\mathrm{Cu}$ specimens were prepared and tested to compare their corrosion resistances under aqueous seawater conditions. The mechanically polished $\mathrm{Cu}$ samples were prepared by a handsanding process of graphene-coated $\mathrm{Cu}$ using a 2000 grit SiC paper to achieve a Cu surface in compliance with ASME surfacefinish standards. Graphene-coated $\mathrm{Cu}$ specimens were prepared by using a drop of acetone as a C source in an RTA system under vacuum, as described previously. Furthermore, the number of graphene layers was varied from one to four using the conventional PMMA transfer method ${ }^{\mathbf{1 2 - 1 4}}$ to investigate the effect of layer thickness on corrosion characteristics. Potentiodynamic polarization and electrochemical impedance spectroscopy (EIS) were performed in an aerated aqueous solution of $\sim 3.0-3.5 \%$ $(\mathrm{w} / \mathrm{v}) \mathrm{NaCl}$, which is a representative condition of seawater at room temperature. An electrochemical cell was composed of three electrodes including a specimen (as-received, mechanically polished, or graphene-coated $\mathrm{Cu}$ ) with an exposed area of $0.25 \mathrm{~cm}^{2}$ as the working electrode, a platinum wire as the counter electrode, and a saturated calomel electrode (SCE) as the reference electrode. The detailed three-electrode cell configuration for the electrochemical corrosion test is shown in Fig. S1. $\dagger$ A fluctuation of the open circuit potential (OCP) of less than $10 \mathrm{mV}$ was considered as a stable potential before carrying out the corrosion tests. Potentiodynamic polarization tests were performed at a scan rate of $2 \mathrm{mV} \mathrm{s}^{-1}$. All potentials were scanned linearly in the noble direction from the cathodic region, 
starting at $-200 \mathrm{mV}$ relative to the corrosion potential $\left(E_{\text {corr }}\right)$. EIS tests were performed by applying a sinusoidal potential wave at $0 \mathrm{~V}(v s$. OCP) with an amplitude of $10 \mathrm{mV}$. The impedance response was measured over the frequency range between 0.01 and $10^{6} \mathrm{~Hz}$, recording to 10 points per decade of frequency using a frequency response analyzer (Solartron, SI 1260, Impedance/Gain Phase Analyser) in combination with a Potentiostat/Gavanostat PAR Model 273A.

\section{Results and discussion}

Fig. 1 schematically illustrates our process for the facile synthesis of monolayer graphene layers converted from a drop of acetone on $\mathrm{Cu}$ surfaces and shows an example of the studied graphene/Cu samples that were prepared as follows: we first eliminated spontaneous amorphous $\mathrm{C}$ fragments existing on the as-received $\mathrm{Cu}$ surfaces by simple heat treatment at $\sim 600^{\circ} \mathrm{C}$ in an RTA system under vacuum. We have consistently observed the significant presence of $\mathrm{C}(\sim 20 \%)$ and $\mathrm{O}(\sim 35 \%)$ atoms at the surface of the as-received $\mathrm{Cu}$ foils (not shown here). This phenomenon has been observed, regardless of the thickness or the manufacturer of the $\mathrm{Cu}$ foils. After the thermal preannealing process of the as-received $\mathrm{Cu}$ foils at $600{ }^{\circ} \mathrm{C}$ for $20 \mathrm{~min}$, there exists a significant decrease in the integrated $\mathrm{C} 1 \mathrm{~s}$ peak intensity from XPS spectra (Fig. 2a), implying that a

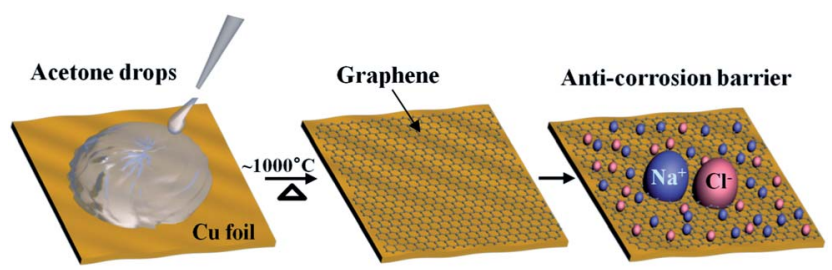

Fig. 1 Schematic illustration of graphene growth converted from acetone drops as anti-corrosion barriers.

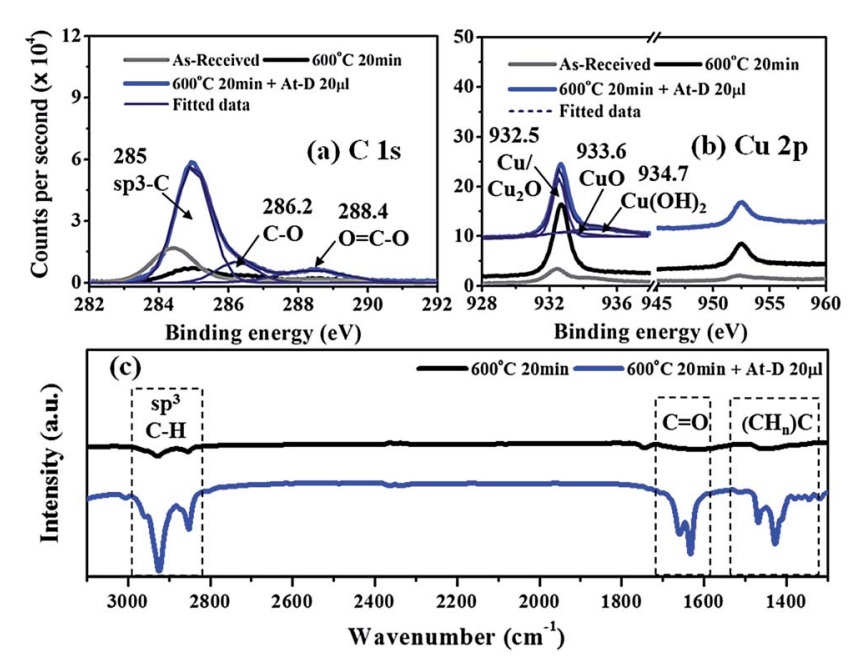

Fig. 2 (a) XPS C 1s, (b) XPS Cu 2p, (c) ATR-FTIR spectra; as-received, pre-annealed (at $600{ }^{\circ} \mathrm{C}$ for $20 \mathrm{~min}$ ) and a drop of acetone-deposited (At-D $20 \mu$ l) samples. considerable number of $\mathrm{C}$ atoms on $\mathrm{Cu}$ surfaces disappeared after the thermal annealing process. From ref. 25 and 26, it was reported that amorphous $\mathrm{C}$ fragments on $\mathrm{Cu}$ surfaces undergo thermal decomposition and/or oxidation in the temperature range of $300-600{ }^{\circ} \mathrm{C}$ and they prefer to desorb in the forms of $\mathrm{CH}_{x}$, $\mathrm{CO}$, and $\mathrm{CO}_{2}$ molecules on the catalytic surface.

After the thermal pre-annealing process of the $\mathrm{Cu}$ foils, a drop of acetone $\left(\sim 20 \mu \mathrm{l} \mathrm{cm}^{-2}\right)$ was applied on the $\mathrm{Cu}$ surface. The acetone was uniformly coated on the $\mathrm{Cu}$ surface by a spincoating process and dried under ambient conditions. From XPS spectra, it was found that the $\mathrm{C}$ atoms exist in three different forms based on their binding energy: (1) $\mathrm{sp}^{3}-\mathrm{C}$ at $285.0 \mathrm{eV}$, (2) ether $(\mathrm{C}-\mathrm{O})$ at $286.2 \mathrm{eV}$, and $(3)$ carboxylate carbon $(\mathrm{O}-\mathrm{C}=\mathrm{O})$ at 288.4 eV (Fig. 2a). Regarding $\mathrm{Cu}$ atoms, they also exist in three different forms: (1) $\mathrm{Cu}$ metal/ $\mathrm{Cu}_{2} \mathrm{O}$ (cuprous oxide) at $932.5 \mathrm{eV}$, (2) cupric oxide $(\mathrm{CuO})$ at $933.6 \mathrm{eV}$, and (3) copper hydroxide $\mathrm{Cu}(\mathrm{OH})_{2}$ at $934.7 \mathrm{eV}$ (Fig. 2b). After depositing acetone molecules on $\mathrm{Cu}$, there exists a remarkable increase in the integrated $\mathrm{C}$ 1s peak intensity related to groups of $\mathrm{sp}^{3}-\mathrm{C}$, along with the increase of oxidized $\mathrm{C}$ containing $\mathrm{C}=\mathrm{O}$ and $\mathrm{O}=\mathrm{C}-\mathrm{O}$. Comparison of ATR FT-IR spectra of the $\mathrm{Cu}$ foils before and after depositing acetone molecules on $\mathrm{Cu}$ surfaces also supports the XPS results that a significant number of C-containing molecules such as $\mathrm{sp}^{3} \mathrm{C}-\mathrm{H},\left(\mathrm{CH}_{n}\right) \mathrm{C}$ and $\mathrm{C}=\mathrm{O}$ are present on the $\mathrm{Cu}$ surface after applying a drop of acetone, as shown in Fig. 2c.

The acetone-coated $\mathrm{Cu}$ foils were then annealed at high temperatures over $800{ }^{\circ} \mathrm{C}$ using an RTA system under vacuum ( $\sim 10^{-3}$ Torr). Fig. 3a shows the comparison of XPS $\mathrm{C} 1 \mathrm{~s}$ peaks before and after the RTA process at $1000{ }^{\circ} \mathrm{C}$ for $3 \mathrm{~min}$. A considerable shift of the $\mathrm{C} 1 \mathrm{~s}$ peak from about 285.0 to $284.5 \mathrm{eV}$ indicates that the C-containing functionalities from acetone drops on $\mathrm{Cu}$ surfaces were converted to a great variety of crystalline structures, which correspond to transition of $\mathrm{sp}^{3}-\mathrm{C}$ fragments to $\mathrm{sp}^{2}$ larger aromatic clusters, along with the reduction of oxygenated carbons $(\mathrm{C}=\mathrm{O}$ and $\mathrm{O}-\mathrm{C}=\mathrm{O})$.

Fig. $3 \mathrm{~b}$ shows the results of Raman spectra of the resulting film on a Cu surface after the RTA process at temperatures in the range between 800 and $1050{ }^{\circ} \mathrm{C}$ for $3 \mathrm{~min}$ under vacuum. The Raman spectra show three primary features: a D band at $\sim 1349 \mathrm{~cm}^{-1}$, a G band at $\sim 1593 \mathrm{~cm}^{-1}$, and a 2D band at $\sim 2687 \mathrm{~cm}^{-1}$ : all of which are expected peak positions of graphene. ${ }^{12-16,27,28}$ We note that graphene grew on both the front and back sides of the $\mathrm{Cu}$ foil under all investigated growth conditions and there exists no significant differences in structural quality of graphene films grown on both sides of the $\mathrm{Cu}$ foil (Fig. S2 and S3†). At this time, the precise growth mechanism of graphene on both sides of $\mathrm{Cu}$ foil is not well understood. However, we believe that the graphene growth on both sides of the $\mathrm{Cu}$ foil samples was achieved by diffusion of dissociated C-containing precursors from the front side to the back side of the $\mathrm{Cu}$ foil considering the very high tracer diffusion constants of C-containing precursors on a $\mathrm{Cu}$ surface. ${ }^{29}$ The precise mechanism will have to be investigated further. Graphene films grown over $1000{ }^{\circ} \mathrm{C}$ show the following characteristics in Raman spectra: (i) a ratio of G-to-2D peak intensities of less than $\sim 0.5$, (ii) a full width at half maximum value of $\sim 37 \mathrm{~cm}^{-1}$ for the $2 \mathrm{D}$ band, and (iii) a ratio of D-to-G peak 
(a)

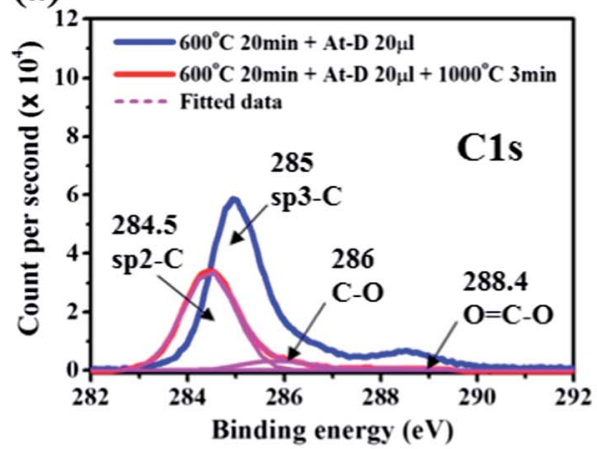

(b)

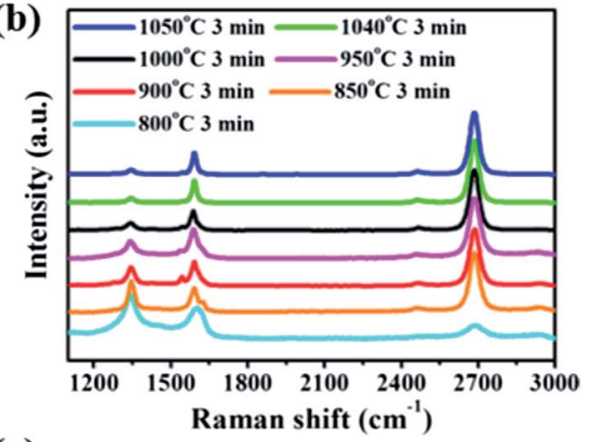

(c)

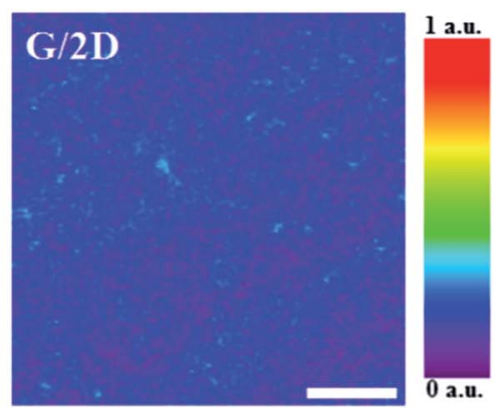

Fig. 3 (a) XPS C 1s peak comparison before and after graphene formation on $\mathrm{Cu}$, and (b) Raman spectra of graphene films with temperature variation. (c) Raman map image of the G/2D bands of graphene grown at temperature $1000^{\circ} \mathrm{C}$ for $3 \mathrm{~min}$ (scale bar, $20 \mu \mathrm{m}$ ), Raman spectra were recorded after transferring onto a $300 \mathrm{~nm} \mathrm{SiO} / 2 / \mathrm{Si}$ surface.

intensities of less than $\sim 0.1$, indicating the formation of monolayer graphene sheets with relatively high crystallinity, which are similar to the previous reported graphene sheets grown by CVD on $\mathrm{Cu}^{12-14}$ Specifically, the Raman spectrum of the graphitic layer obtained after the RTA process at $800{ }^{\circ} \mathrm{C}$ shows a broad and high-intensity D band; however, the values of the D-to-G intensity ratio and the $2 \mathrm{D}$ peak intensity significantly drop and increase, respectively, as the temperature increased from 800 to $1000{ }^{\circ} \mathrm{C}$, indicating that the formation of graphene on a $\mathrm{Cu}$ surface is thermally activated. ${ }^{27}$ Raman mapping of the G-to-2D intensity ratio over an $80 \times 80 \mu \mathrm{m}^{2}$ area was performed to evaluate the uniformity and coverage of the acetone-derived graphene films grown at $1000{ }^{\circ} \mathrm{C}$ on a large scale, and it was found that the monolayer coverage is close to $100 \%$ in the material (Fig. 3c).

In order to assess the feasibility of potential offshore applications of graphene, the corrosion behaviors of acetone-derived graphene films as protective coating layers of $\mathrm{Cu}$ were characterized under aqueous conditions of seawater. The test condition of $\sim 3.0-3.5 \%$ sodium chloride concentration (equivalent to $0.5-0.6 \mathrm{M} \mathrm{NaCl}$ ) was selected to represent the seawater condition, because the aggressiveness of the $\mathrm{Cu}$ corrosion is known to be proportional to the chlorine $(\mathrm{Cl})$ ion concentration in contact with the metal surface. ${ }^{30,31}$ The corrosion process of the asreceived and mechanically polished $\mathrm{Cu}$ samples is comprised of anodic oxidation reaction $\left(\mathrm{Cu} \rightarrow \mathrm{Cu}^{2+}+2 \mathrm{e}^{-}\right)$and cathodic reduction reaction $\left(\mathrm{O}_{2}+2 \mathrm{H}_{2} \mathrm{O}+4 \mathrm{e}^{-} \rightarrow 4 \mathrm{OH}^{-}\right.$, either water or $\mathrm{O}$ reduction). The graphene-coated samples exhibit much lower affinity toward $\mathrm{O}$ reduction, i.e., an anti-corrosion barrier between aggressive $\mathrm{Cl}$ ions in the solution and the $\mathrm{Cu}$ surface.

Fig. 4a shows the measured potentiodynamic polarization curves in a $3.5 \%$ sodium chloride solution for the as-received, mechanically polished, and acetone-derived graphene-coated $\mathrm{Cu}$ samples. The corrosion current $\left(I_{\text {corr }}\right)$ of graphene-coated $\mathrm{Cu}$ was reduced 56 and 59 times lower than those of the as-received and mechanically polished $\mathrm{Cu}$ surfaces, respectively. In addition, the corrosion potential $\left(E_{\text {corr }}\right)$ shifted towards more negative values. Fig. $4 \mathrm{~b}-\mathrm{d}$ show the secondary electron microscopy (SEM) images and the corresponding energy dispersive spectroscopy (EDS) data in the selected region of each sample after the corrosion tests. From Fig. $4 \mathrm{~b}$ and c, it is seen that the penetration into the outermost layer by attractive $\mathrm{Cl}$, dissolved $\mathrm{O}$, and neutral water could lead to oxidation of the whole surface. The strong $\mathrm{O}$ and little $\mathrm{Cl}$ peaks of the as-received and mechanically polished $\mathrm{Cu}$ samples demonstrate that the $\mathrm{CuCl}$ film formed at higher $\mathrm{Cl}$ concentrations $(>0.1 \mathrm{M})$ and was subsequently transformed to an oxide film by hydrolysis of the

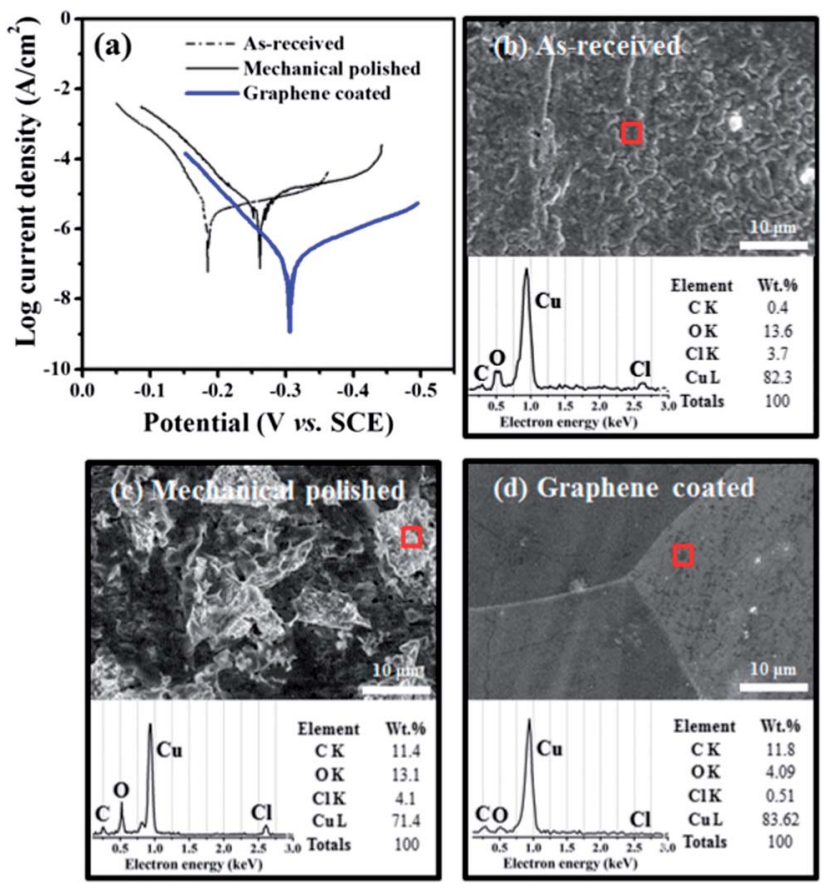

Fig. 4 (a) Potentiodynamic polarization test and (b-d) SEM-EDS analysis on the square box of each sample after the test; as-received, mechanically polished and graphene-coated $\mathrm{Cu}$ in $3.5 \% \mathrm{NaCl}$ solution. 
film in the presence of dissolved $\mathrm{O}$ in solution $\left(2 \mathrm{Cu}^{+}+2 \mathrm{Cl}^{-}=\right.$ $\left.2 \mathrm{CuCl}, 2 \mathrm{CuCl}+\mathrm{H}_{2} \mathrm{O} \rightarrow \mathrm{Cu}_{2} \mathrm{O}+2 \mathrm{H}^{+}+2 \mathrm{Cl}^{-}\right)$. As shown in Fig. $4 \mathrm{~d}$, however, we observed that there existed much lower $\mathrm{O}$ and $\mathrm{Cl}$ concentrations on the surface of the graphene-coated sample and no significant changes (or defects) on the Cu surface except a trace of white salts. Ultimately, large suppression of the cathodic reaction by the graphene coating layer resulted in both a crucial reduction of $I_{\text {corr }}$ and simultaneously the negative shift of $E_{\text {corr }}$ of graphene-coated $\mathrm{Cu}$, which confirms the ability of the graphene coating to prevent penetration of dissolved oxygen and aggressive chlorine ions into the underlying metal. ${ }^{23}$

The EIS measurement of the electrochemical technique is known to be used to evaluate the electrochemical corrosion reactions of a coating layer in the interface between electroactive ionic species and the metal surface. ${ }^{32}$ The Bode (or Nyquist) plot is the most common representation of the process occurring at various interfaces because the electrochemical impedance is a complex number with a real component, $Z_{\text {real }}$ and an imaginary component, $Z_{\text {imaginary }}$. A small sinusoidal perturbation was applied to the sample under examination and the impedance modulus $|Z|$ was recorded as a function of frequency $\omega\left(2 \pi f\right.$, where $f=$ frequency in Hertz). ${ }^{33} Z_{\text {real }}$ was measured by the total diameter of the semicircle in the Nyquist plot, which is the magnitude of the impedance at the lowest frequency, i.e. corrosion resistance. Fig. 5 shows the results of EIS measurement in this study including the Nyquist plot $\left(Z_{\text {imaginary }}\right.$ vs. $Z_{\text {real }}$, Fig. 5a), Bode plot $(|Z| v s . \log \omega$, Fig. $5 \mathrm{~b})$ and phase angle $(\theta$ vs. $\log \omega$, Fig. $5 \mathrm{c})$ for the as-received, mechanically polished, and graphene-coated $\mathrm{Cu}$ samples, and the simulated equivalent circuit (Fig. 5d). In the inset of Fig. 5a, the Nyquist plot of both as-received and mechanically polished $\mathrm{Cu}$ samples consisted of two different stages with a semicircle and a linear region; the semicircular region was attributed to the sum of small charge transfer capacity between $\mathrm{Cu}$ and its oxide
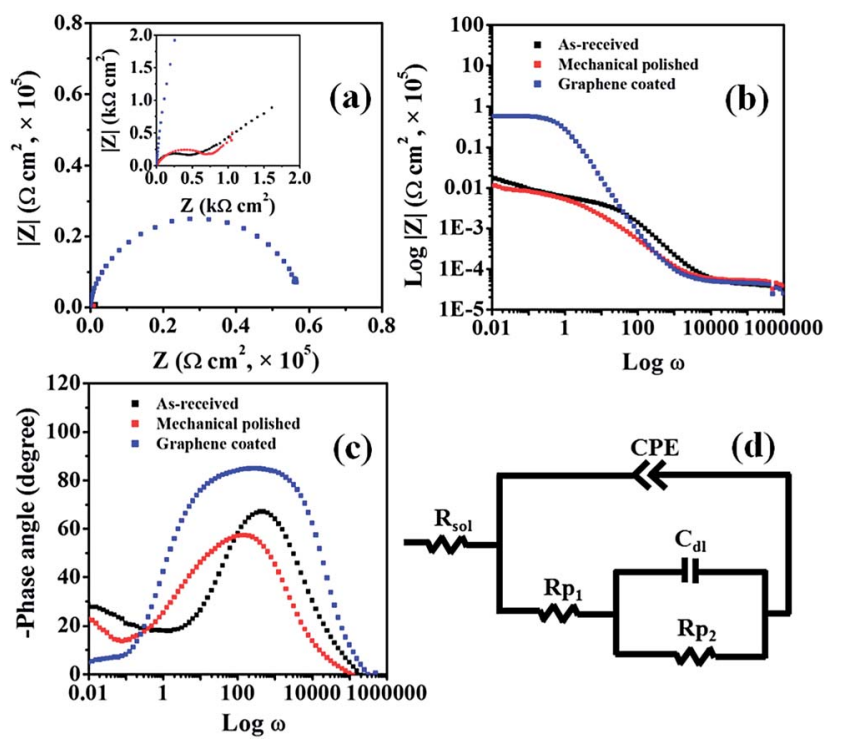

Fig. 5 EIS test results of as-received, mechanically polished and graphene-coated $\mathrm{Cu}$ in 3.5\% NaCl solution: (a) Nyquist plot, (b) Bode plot, (c) phase angle, and (d) simulated equivalent circuit. films, while the linear region was related to the resistance against the diffusion of corrosive species through the pores of the oxide film in the electrolyte/oxide/metal configuration. In Fig. 5a and b, Nyquist and Bode plots of graphene-coated $\mathrm{Cu}$ follow the trend of large capacitive impedance behavior, which is capable of protecting against penetration of the attractive active species because graphene coating decreases the probability of dissolved oxygen, water, and chloride ions penetrating onto the $\mathrm{Cu}$ surface. In the phase angle plot obtained for graphene-coated $\mathrm{Cu}$ (Fig. 5c), the minimum of the phase angle was close to -90 degrees in a wide range of frequency, corresponding to good coating quality. For the as-received and mechanically polished $\mathrm{Cu}$ samples, the diffusion process, especially in the low frequency range, was observed with a minimum phase angle of about -70 and -60 degrees, respectively. Table 1 summarizes the parameter values and compiles the detailed illustration of information obtained by fitting experimental data with the equivalent circuit configuration represented in Fig. 5d. The electrolyte/metal interface capacitance $\left(C_{\mathrm{dl}}\right)$ of graphene-coated $\mathrm{Cu}$ was about three and four orders of magnitude lower than those of as-received and mechanically polished $\mathrm{Cu}$, respectively. Thus, the relatively lower $C_{\mathrm{dl}}$ of graphene-coated $\mathrm{Cu}$ indicates a comparatively lower exposure of the $\mathrm{Cu}$ surface to active species such as dissolved oxygen or chloride ions, since the capacitance is directly proportional to the area of the capacitor. However, the $C_{\mathrm{dl}}$ of graphene-coated $\mathrm{Cu}$ in a relatively high chlorine concentration of $0.6 \mathrm{M} \mathrm{NaCl}$ was approximately 3 times higher than that in $0.1 \mathrm{M} \mathrm{NaCl},{ }^{22}$ but 6.4 times lower than that in $0.1 \mathrm{M} \mathrm{Na}_{2} \mathrm{SO}_{4} \cdot{ }^{24}$ The constant phase element (CPE) of graphene-coated $\mathrm{Cu}$ suggests a density of conductive pathway approximately two orders of magnitude lower than those of as-received and mechanically polished $\mathrm{Cu}$. The CPE value is 2.7 times higher than that in $0.1 \mathrm{M} \mathrm{NaCl}^{22}$ and over 10 times lower than the value in $0.1 \mathrm{M} \mathrm{Na}_{2} \mathrm{SO}_{4}{ }^{24}$ This demonstrates that the corrosion inhibition performance of the acetone-derived graphene coating is comparable with that of CVD-grown graphene. The exponent of

Table 1 Equivalent circuit parameters of as-received, mechanically polished, monolayer graphene coated $\mathrm{Cu}$ in $3.5 \% \mathrm{NaCl}$ solution (compared with cited reference values)

\begin{tabular}{llllll}
\hline Sample & $C_{\mathrm{dl}}{ }^{a}$ & \multicolumn{1}{c}{$\mathrm{CPE}^{b}$} & $n^{c}$ & \multicolumn{1}{c}{$R_{\text {corr }}{ }^{d}$} & $\mathrm{IE}^{e}$ \\
\hline As-received & $3.4 \times 10^{-3}$ & $0.4 \times 10^{-4}$ & 0.78 & $1.8 \times 10^{3}$ & - \\
Mechanically & $1.6 \times 10^{-2}$ & $1.6 \times 10^{-4}$ & 0.74 & $1.6 \times 10^{3}$ & - \\
polished & & & & & \\
At-D graphene & $1.4 \times 10^{-6}$ & $2.0 \times 10^{-6}$ & 0.8 & $6 \times 10^{4}$ & 97.4 \\
CVD-graphene $^{22}$ & $4.6 \times 10^{-7}$ & $5.4 \times 10^{-6}$ & 0.9 & $6.2 \times 10^{5}$ & $97^{f}$ \\
CVD-graphene $^{24}$ & $9.4 \times 10^{-6}$ & $0.85 \times 10^{-5}$ & 0.8 & $1 \times 10^{4}$ & $71^{g}$
\end{tabular}

${ }^{a} C_{\mathrm{dl}}$ : electrolyte/metal interface capacitance. ${ }^{b} \mathrm{CPE}$ (constant phase element): density of conductive pathways of graphene (or oxide). ${ }^{c} n$ : exponent value of CPE, capacitor if $n$ is close to 1 , resistor if $n$ is close to $0 .{ }^{d}$ Corrosion resistance $\left(R_{\text {corr }}, \Omega \mathrm{cm}^{2}\right)=R_{\mathrm{p} 1}+R_{\mathrm{p} 2}=$ total $R_{\mathrm{p}}$ (or total $R_{\mathrm{ct}}$ ); $R_{\mathrm{p} 1}$ : resistance against electrolyte exposure to graphene (or oxide) through pore/defects. $R_{\mathrm{p} 2}$ : interface resistance between the electrolyte and the graphene (or oxide) $/ \mathrm{Cu}$ system. ${ }^{e}$ Inhibition efficiency $(\mathrm{IE}, \%)=\left\{\left(R_{\mathrm{p}, \text { coated }}-R_{\mathrm{p}}\right) / R_{\mathrm{p} \text {,coated }}\right\} \times 100 .{ }^{f} R_{\text {corr }}$ of mechanically polished $\mathrm{Cu}=1.58 \times 10^{4}$, in $0.1 \mathrm{M} \mathrm{NaCl} .{ }^{g} R_{\text {corr }}$ of mechanically polished $\mathrm{Cu}=2.95 \times 10^{3}$, in $0.1 \mathrm{M} \mathrm{Na}_{2} \mathrm{SO}_{4}$. 
CPE, $n$, of all samples is close to 1 and indicates capacitor behaviour. The corrosion resistance $\left(R_{\mathrm{corr}}, \Omega \mathrm{cm}^{2}\right)$ can be considered the mathematical sum of polarization resistances in the simulated equivalent circuit, which indicates both polarization resistance $\left(R_{\mathrm{p} 1}\right)$ against electrolyte exposure to graphene (or oxide) through pores/defects and interface polarization resistance $\left(R_{\mathrm{p} 2}\right)$ between the electrolyte and graphene/Cu (or oxide/Cu). $R_{\text {corr }}$ can be determined by reading the Bode plot in the logarithm impedance of the $y$ axis real part in the lowest frequency or by extrapolating the Nyquist plot to the $x$ axis real part as the frequency approaches $0 \mathrm{~Hz} \cdot{ }^{33}$ From the experiments, it was found that the $R_{\text {corr }}$ of graphene-coated $\mathrm{Cu}\left(6 \times 10^{4} \Omega\right.$ $\mathrm{cm}^{2}$ ) was 33.3 times and 37.5 times higher than those of asreceived $\mathrm{Cu}\left(1.8 \times 10^{3} \Omega \mathrm{cm}^{2}\right)$ and mechanically polished $\mathrm{Cu}$ $\left(1.6 \times 10^{3} \Omega \mathrm{cm}^{2}\right)$, respectively. Furthermore, the $R_{\text {corr }}$ value in this study is approximately one order of magnitude lower than that reported for $0.1 \mathrm{M} \mathrm{NaCl}^{22}$ and 6 times higher than that reported for $0.1 \mathrm{M} \mathrm{Na}_{2} \mathrm{SO}_{4} \cdot{ }^{24}$ Therefore, the inhibition efficiency (IE) can be calculated from the corrosion resistance of mechanically polished and graphene-coated $\mathrm{Cu}$. Note that the IE obtained by corrosion resistance increases in the order of $0.6 \mathrm{M} \mathrm{NaCl}(97.4 \%)>0.1 \mathrm{M} \mathrm{NaCl}(97 \%)>0.1 \mathrm{M} \mathrm{Na}_{2} \mathrm{SO}_{4}(71 \%)$ solution. Therefore, we concluded that the corrosion inhibition performance of mechanically polished $\mathrm{Cu}$ rapidly drops due to the high chloride concentration, while graphene-coated $\mathrm{Cu}$ effectively countervails against oxygen and chloride penetration regardless of the ambient environment.

In order to compare the corrosion inhibition performance of graphene coating with conventional coating methods such as polymer coatings, we performed a comparative experiment with PMMA-coated $\mathrm{Cu}$ samples. Table 2 shows the summary of equivalent circuit parameters of monolayer graphene-coated $\mathrm{Cu}$ and PMMA-coated $\mathrm{Cu}$ in $3.5 \% \mathrm{NaCl}$ solution. Considering that the thickness of the PMMA coating used in this study is about $100 \mathrm{~nm}$, it was found that the coating by monolayer graphene could achieve corrosion inhibition equivalent or comparable to the relatively thick PMMA coating.

We also attempted to demonstrate the excellent performance of multi-layer graphene sheets as a pathway to form a more reliable corrosion inhibition coating layer in corrosive environments. In this case, the multi-layered graphene sheets were obtained using the conventional PMMA transfer method, ${ }^{\mathbf{1 2 - 1 4 , 2 8}}$ which resulted in almost continuous coverage and the

Table 2 Equivalent circuit parameters of monolayer graphene-coated $\mathrm{Cu}$ and PMMA-coated $(100 \mathrm{~nm}) \mathrm{Cu}$ in $3.5 \% \mathrm{NaCl}$ solution

\begin{tabular}{llllr}
\hline Sample & $C_{\mathrm{dl}}{ }^{a}$ & $\mathrm{CPE}^{b}$ & $n^{c}$ & \multicolumn{1}{c}{$R_{\text {corr }}{ }^{d}$} \\
\hline At-D graphene & $1.4 \times 10^{-6}$ & $2.0 \times 10^{-6}$ & 0.8 & $6 \times 10^{4}$ \\
PMMA & $6.3 \times 10^{-8}$ & $3.6 \times 10^{-6}$ & 0.5 & $6.1 \times 10^{4}$
\end{tabular}

${ }^{a} C_{\mathrm{dl}}$ : electrolyte/metal interface capacitance. ${ }^{b} \mathrm{CPE}$ (constant phase element): density of conductive pathways of graphene (or oxide). ${ }^{c} n$ : exponent value of CPE, capacitor if $n$ is close to 1 , resistor if $n$ is close to $0 .{ }^{d}$ Corrosion resistance $\left(R_{\text {corr }}, \Omega \mathrm{cm}^{2}\right)=R_{\mathrm{p} 1}+R_{\mathrm{p} 2}=$ total $R_{\mathrm{p}}$ (or total $R_{\mathrm{ct}}$ ); $R_{\mathrm{p} 1}$ : resistance against electrolyte exposure to graphene (or oxide) through pore/defects. $R_{\mathrm{p} 2}$ : interface resistance between the electrolyte and the graphene (or oxide)/Cu system. corrosion tests were conducted in $0.5 \mathrm{M} \mathrm{NaCl}$ solutions. Note that the monolayer is denoted as ' $1 \mathrm{~L}$ ', bi-layer as ' $2 \mathrm{~L}$ ', and fourlayer as ' $4 \mathrm{~L}$ '. As shown in Fig. 6 and fitted data of Table 3, the $R_{\text {corr }}$ values of $2 \mathrm{~L}$ and $4 \mathrm{~L}$ graphene-coated Cu were increased to 3.6 times and 5.8 times higher than that of the $1 \mathrm{~L}$ graphenecoated $\mathrm{Cu}$ sample, respectively. Furthermore, the IEs of 1L, 2L, and $4 \mathrm{~L}$ graphene-coated $\mathrm{Cu}$ were recorded as 93,98 , and $99 \%$ of the mechanically polished $\mathrm{Cu}$ sample, respectively. From the results of this study, multi-layer stacked graphene is one solution to achieve the maximum IE by blocking the pathway of dissolved oxygen and chloride ion intrusion through defects of graphene into the underlying $\mathrm{Cu}$ surface. The SEM image obtained after the EIS measurement test (Fig. S4†) shows the formation of corrosion products of centered white colored lines and dark shade diffusion traces of dissolved oxygen or moisture along the grain boundary of the single-layer graphene with a domain size of $\sim 5 \mu \mathrm{m}$. This fact provides the evidence that the active species prefer a diffusion pathway through grain boundaries or defect sites on the graphene surface due to the basal plane's hydrophobic properties. ${ }^{34}$ Bright white dot impurities formed on the graphene basal plane originating from the
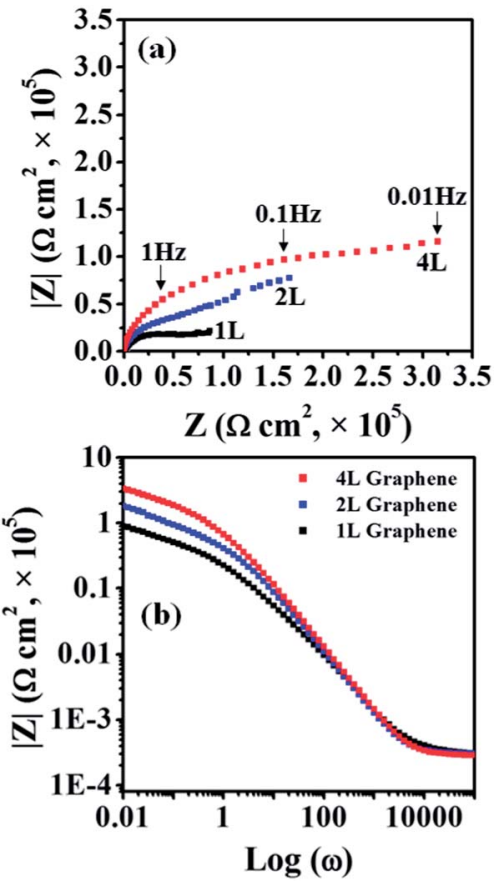

Fig. 6 EIS test results of mono-, bi-, and four-layered graphenecoated $\mathrm{Cu}$ in $3.0 \% \mathrm{NaCl}$ solution: (a) Nyquist and (b) Bode plot.

Table 3 Equivalent circuit parameters for mechanically polished, and $1 \mathrm{~L}, 2 \mathrm{~L}$, and $4 \mathrm{~L}$ graphene coated copper in $3 \% \mathrm{NaCl}$ solution

\begin{tabular}{lllll}
\hline Sample & $C_{\mathrm{dl}}$ & $\mathrm{CPE}$ & $R_{\text {corr }}$ & $\mathrm{IE}$ \\
\hline $\begin{array}{l}\text { Mechanically } \\
\text { polished }\end{array}$ & $2.1 \times 10^{-3}$ & $5.6 \times 10^{-4}$ & $7.2 \times 10^{3}$ & - \\
$\begin{array}{l}\text { 1L graphene } \\
\text { 2L graphene }\end{array}$ & $1.5 \times 10^{-6}$ & $1.3 \times 10^{-5}$ & $1.0 \times 10^{5}$ & 93 \\
4L graphene & $1.3 \times 10^{-6}$ & $8.6 \times 10^{-6}$ & $3.6 \times 10^{5}$ & 98 \\
& $1.1 \times 10^{-6}$ & $4.2 \times 10^{-6}$ & $5.8 \times 10^{5}$ & 99
\end{tabular}


stripe structure of as-received $\mathrm{Cu}$ have not reacted with the underlying $\mathrm{Cu}$.

\section{Conclusion}

We demonstrate the excellent performance of acetone-derived graphene films as corrosion inhibition coatings in a seawater environment. Single-layer graphene is uniformly grown on $\mathrm{Cu}$ surfaces using a drop of acetone by an RTA process and the structural quality of the resulting films is comparable to common graphene grown by CVD. We note that the passivation mechanism of monolayer graphene coatings follows characteristics of large cathodic reduction barriers against dissolved oxygen and chloride diffusion into underlying $\mathrm{Cu}$ in a seawater environment. We also demonstrate a pathway to form a more reliable corrosion inhibition coating layer in corrosive environments by using multi-layer graphene sheets on $\mathrm{Cu}$ substrates. Although partial active oxidation may occur at grain boundaries or defect sites of the monolayer graphene, it is worthwhile to note that the multi-layer stacked graphene is effective in blocking the pathway of dissolved oxygen and chloride ion intrusion through defects of graphene into the underlying $\mathrm{Cu}$ surface. With further development in graphene growth with a single domain or defined control of graphene layer thickness, we expect a significant enhancement in the anti-corrosion performance of not only $\mathrm{Cu}$ but also a variety of metals and alloys for potential offshore applications.

\section{Acknowledgements}

This work was supported by the UNIST Future Challenge Project (Grant no. 1.130012.01), by the development program of local science park funded by the ULSAN Metropolitan City, by the National Research Foundation (NRF) funded by the Korean government through the Midcareer Researcher Program (Grant no. NRF-2013R1A2A2A04015946) and by the Energy Research and Development Program of the Korea Institute of Energy Technology Evaluation and Planning (KETEP) grant funded by the Korea Government Ministry of Trade Industry and Energy (MOTIE).

\section{References}

1 R. F. North and M. J. Pryor, Corros. Sci., 1969, 9, 509-512.

2 R. F. North and M. J. Pryor, Corros. Sci., 1970, 10, 297-311.

3 E. E. Stansbury and R. A. Buchanan, Fundamentals of Electrochemical Corrosion, ASM International, Materials Park, OH, USA, 2000.

4 M. I. Redondo and C. B. Breslin, Corros. Sci., 2007, 49, 17651776.

5 M. Stratmann, R. Feser and A. Leng, Electrochim. Acta, 1994, 39, 1207-1214.

6 B. V. A. Rao, M. Y. Iqbal and B. Sreedhar, Corros. Sci., 2009, 51, 1441-1452.

7 M. Segarra, L. Miralles, J. Diaz, H. Xuriguera, J. M. Chimenos, F. Espiell and S. Pinol, Mater. Sci. Forum, 2003, 426, 3511-3516.
8 K. S. Novoselov, A. K. Geim, S. V. Morozov, D. Ziang, Y. Zhang, S. V. Dubonos, I. V. Grigorieva and A. A. Firsov, Science, 2004, 306, 666-669.

9 K. I. Bolotin, K. J. Sikes, Z. Jiang, M. Klima, G. Fudenberg, J. Hone, P. Kim and H. L. Stormer, Solid State Commun., 2008, 146, 351-355.

10 A. A. Balandin, S. Ghosh, W. Bao, I. Calizo, D. Teweldebrhan, F. Miao and C. N. Lau, Nano Lett., 2008, 8, 902-907.

11 S.-Y. Kwon, C. V. Ciobanu, V. Petrova, V. B. Shenoy, J. Bareno, V. Gambin, I. Petrov and S. Kodambaka, Nano Lett., 2009, 9, 3985-3990.

12 X. Li, W. Cai, J. An, S. Kim, J. Nah, D. Yang, R. Piner, A. Velamakanni, I. Jung, E. Tutuc, S. K. Banerjee, L. Colombo and R. S. Ruoff, Science, 2009, 324, 13121314.

13 A. Reina, X. Jia, J. Ho, D. Nezich, H. Son, V. Bulovic, M. S. Dresselhaus and J. Kong, Nano Lett., 2009, 9, 30-35.

14 S. Bae, H. Kim, Y. Lee, X. Xu, J.-S. Park, Y. Zheng, J. Balakrishnan, T. Lei, H. R. Kim, Y. I. Song, Y.-J. Kim, K. S. Kim, B. Özyilmaz, J.-H. Ahn, B. H. Hong and S. Lijima, Nat. Nanotechnol., 2010, 4, 574-578.

15 M. Wang, S. K. Jang, W.-J. Jang, M. Kim, S.-Y. Park, S.-W. Kim, S.-J. Kahng, J.-Y. Choi, R. S. Ruoff, Y. J. Song and S. Lee, Adv. Mater., 2013, 25, 2746-2752.

16 J. Kwak, J. H. Chu, J.-K. Choi, S.-D. Park, H. Go, S. Y. Kim, K. Park, S.-D. Kim, Y.-W. Kim, E. Yoon, S. Kodambaka and S.-Y. Kwon, Nat. Commun., 2012, 3, 645.

17 J.-K. Choi, J.-H. Huh, S.-D. Kim, D. Moon, D. Yoon, K. Joo, J. Kwak, J. H. Chu, S. Y. Kim, K. Park, Y.-W. Kim, E. Yoon, H. Cheong and S.-Y. Kwon, Nanotechnology, 2012, 23, 435603.

18 S. Chen, L. Brown, M. Levendorf, W. Cai, S.-Y. Ju, J. Edgeworth, X. Li, C. W. Magnuson, A. Velamakanni, R. D. Piner, J. Kang, J. Park and R. S. Ruoff, ACS Nano, 2011, 5, 1321-1327.

19 S. M. Kozlov, F. Viñes and A. Görling, Adv. Mater., 2011, 23, 2638-2643.

20 S. Ryu, L. Liu, S. Berciaud, Y.-J. Yu, H. Liu, P. Kim, G. W. Flynn and L. E. Brus, Nano Lett., 2010, 10, 4944-4951.

21 L. S. Panchakarla, K. S. Subrahmanyam, S. K. Saha, A. Govindaraj, H. R. Krishnamurthy, U. V. Waghmare and C. N. R. Rao, Adv. Mater., 2009, 21, 4726-4730.

22 R. K. S. Raman, P. C. Banerjee, D. E. L. H. Gullapalli, M. Sumandasa, A. Kumar, L. Choudhary, R. Tkacz, P. M. Ajayan and M. Majumder, Carbon, 2012, 50, 40404045.

23 N. T. Kirkland, T. Schiller, N. Medhekar and N. Birbilis, Corros. Sci., 2012, 56, 1-4.

24 D. Prasai, J. C. Tuberquia, R. R. Harl, G. K. Jennings and K. I. Bolotin, ACS Nano, 2012, 6, 1102-1108.

25 P. B. Lukins, D. R. Mckenzie, A. M. Vassallo and J. V. Hanna, Carbon, 1993, 31, 569-575.

26 L. H. Zhang, H. Gong and J. P. Wang, J. Appl. Phys., 2002, 91, 9646-9651.

27 J. H. Chu, J. Kwak, T.-Y. Kwon, S.-D. Park, H. Go, S. Y. Kim, K. Park, S. Kang and S.-Y. Kwon, ACS Appl. Mater. Interfaces, 2012, 4, 1777-1782. 
28 J. Kwak, T.-Y. Kwon, J. H. Chu, J.-K. Choi, M.-S. Lee, S. Y. Kim, H. J. Shin, J.-U. Park and S.-Y. Kwon, Phys. Chem. Chem. Phys., 2013, 15, 10446-10452.

29 O. V. Yazyev and A. Pasquarello, Phys. Rev. Lett., 2008, 100, 156102.

30 F. Arjmand and A. Adriaens, Materials, 2012, 5, 2439-2464.

31 G. Kear, B. D. Barker and F. C. Walsh, Corros. Sci., 2004, 46, 109-135.
32 B.-Y. Chang and S.-M. Park, Annu. Rev. Anal. Chem., 2010, 3, 207-229.

33 Application Note AC-1, Basics of Electrochemical Impedance Spectroscopy (EIS), EG\&G Princeton Applied Research, Princeton, NJ, USA, 1989.

34 T. H. Ly, D. L. Duong, Q. H. Ta, F. Yao, Q. A. Vu, H. Y. Jeong, S. H. Chae and Y. H. Lee, Adv. Funct. Mater., 2013, 23, 51835189. 